Article

\title{
Superhydrophobicity and Durability in Recyclable Polymers Coating
}

\author{
Francesca Cirisano $(\mathbb{D}$ and Michele Ferrari $* \mathbb{C}$ \\ CNR-ICMATE-National Research Council, Institute of Condensed Matter Chemistry and Technologies for Energy, \\ 16149 Genova, Italy; francesca.cirisano@ge.icmate.cnr.it \\ * Correspondence: michele.ferrari@ge.icmate.cnr.it
}

check for updates

Citation: Cirisano, F.; Ferrari, M. Superhydrophobicity and Durability in Recyclable Polymers Coating. Sustainability 2021, 13, 8244. https:// doi.org/10.3390/su13158244

Academic Editors: Mariateresa Lettieri and Asterios Bakolas

Received: 11 June 2021

Accepted: 18 July 2021

Published: 23 July 2021

Publisher's Note: MDPI stays neutral with regard to jurisdictional claims in published maps and institutional affiliations.

Copyright: (c) 2021 by the authors. Licensee MDPI, Basel, Switzerland. This article is an open access article distributed under the terms and conditions of the Creative Commons Attribution (CC BY) license (https:// creativecommons.org/licenses/by/ $4.0 /)$.

\begin{abstract}
Highly hydrophobic and superhydrophobic materials obtained from recycled polymers represent an interesting challenge to recycle and reuse advanced performance materials after their first life. In this article, we present a simple and low-cost method to fabricate a superhydrophobic surface by employing polytetrafluoroethylene (PTFE) powder in polystyrene (PS) dispersion. With respect to the literature, the superhydrophobic surface (SHS) was prepared by utilizing a spraycoating technique at room temperature, a glass substrate without any further modification or thermal treatment, and which can be applied onto a large area and on to any type of material with some degree of fine control over the wettability properties. The prepared surface showed superhydrophobic behavior with a water contact angle (CA) of $170^{\circ}$; furthermore, the coating was characterized with different techniques, such as a 3D confocal profilometer, to measure the average roughness of the coating, and scanning electron microscopy (SEM) to characterize the surface morphology. In addition, the durability of SH coating was investigated by a long-water impact test (raining test), thermal treatment at high temperature, an abrasion test, and in acidic and alkaline environments. The present study may suggest an easy and scalable method to produce SHS PS/PTFE films that may find implementation in various fields.
\end{abstract}

Keywords: superhydrophobic; PTFE; spray coating; self-cleaning

\section{Introduction}

In nature we can observe living systems belonging both to the plant and animal worlds that are able to enhance and manage their surface water repellence, such as the leaf of the Nelumbo nucifera (lotus effect) [1,2], birds and insects' wings, or beetle shields [3,4].

Surfaces exhibiting such an effect show water contact angles (CAs) higher than $150^{\circ}$ and contact angle hysteresis (CAH) less than $5^{\circ}$ where, typically, water drops acquire a spherical shape and can easily roll off without friction on surfaces removing dirt or dust. All surfaces showing these properties are called superhydrophobic (SHS) due to the extreme water repellence given by air pockets formed because of the hierarchical structure (nano-micro scales) of a low surface energy material. The small surface area coming into contact with water droplets results in a reduction in adhesion forces, contact angle hysteresis, and tilt angle [5]. Inspired by nature, researchers have devoted much attention to artificially reproduce the lotus effect, developing, by biomimetic approaches, new kinds of materials with special wettability that may be applicable in everyday life.

While biology can continuously maintain superhydrophobic waxes or other waterrepellent materials [6,7], an important challenge for researchers is the production of a surface with a long lifespan because, to date, artificial self-healing SH surfaces do not provide a comparable long-term performance. In this direction, it is therefore important to produce coatings that have high mechanical strength and, in case of damage, are easily repairable.

Developing superhydrophobic surfaces is of great interest in those cases where protection against water contact is fundamental, including many applications such as self- 
cleaning, membrane for oil separation, waste-water treatments, optical windows, anticorrosion [8-10], anti-fouling [11,12] and drag reduction for ship hulls [13-15], anti-bacteria of medical equipment $[16,17]$, anti-water condensation, anti-icing [18-20], and heat transfer [21]. To obtain an SHS, the coexistence of two basic conditions, such as low surface energy materials and roughness at the micro-nano scale, is necessary [22]; there are two possible ways to achieve this aim: modifying with low surface energy materials a rough surface or making rough a surface with intrinsic low surface energy. There are many methods for producing superhydrophobic surfaces, such as surface etching (chemical, plasma, laser) [23-25], sol-gel [26,27], layer-by-layer self-assembly [28], electrochemical deposition [29], phase separation [30,31], or lithography (photolithography, electron beam, X-ray) [32-34]. With these methods, it is possible to successfully obtain SHS even if they often require high costs and energy consumption, complex routes, no possibility to replace coatings that are damaged, and their application to only small areas. One promising route is the use of spray coating using dispersions that do not need any further treatment after deposition.

Independent of the way in which the SHS is produced, it is important to consider the origin of the starting materials and their cost. Due to this problem, scientists have recently tried to use discarded products from industrial productions [35-37] and urban solid waste [38-40] as starting materials. The use of recycled materials for SHS production allows the environmental impact to be reduced and to create a cheap advanced material. In this study we use recyclable and low-cost polymers such as polytetrafluoroethylene (PTFE) and polystyrene (PS), to fabricate SHS.

PTFE is the fluoropolymer that shows, as an industrial product, the lowest friction coefficient, a low surface energy of $19.4 \mathrm{mN} / \mathrm{m}$ [41], and a higher water CA $=109^{\circ}$. Such behavior is due to its chemical composition and the presence of $-\mathrm{CF}_{3}$ groups fundamental for a hydrophobic interaction with polar liquids. Furthermore, PTFE shows chemical inertia against many compounds, complete insolubility in water and any organic solvent, is cheap, and readily available.

The use of PTFE in the production of superhydrophobic materials is relatively recent and many approaches have been tried and tested. In general, two are the main approaches: roughening a PTFE surface to achieve the superhydrophobicity, such as by plasma etching [42], templating [43], sand paper [44], sanding [45], laser technologies [46-48]; or by deposition on substrate of a thin film of PTFE by a pulsed laser deposition [49], RF plasma sputtering [50], RF-magnetron sputtering [51], supercritical $\mathrm{CO}_{2}$ [52], electrospinning [53], and chemical vapor deposition (CVD) [54]. Today, spray coating is not widespread; however, this method has the advantage of being simple, with a high efficiency and obtaining a good hydrophobicity and, when used, a final heat treatment is often required [55,56].

Moreover, in our work, PS was employed in combination with PTFE. PS is a lowhydrophobicity polymer with a surface tension of $34 \mathrm{mN} / \mathrm{m}$ and a water CA of $90^{\circ}$ [41]. This material was chosen as a matrix with PTFE powder to enhance the film adhesive strength to the substrate [57] because it is low cost; easily available, for example, by recycling PS packaging; and because of its good solubility in non-toxic solvents, such as ethyl acetate (EtOAc).

In the present study, we present an easy and low-cost procedure to produce a PS/PTFE coating with superhydrophobic behavior by a spray technique on glass substrate at room temperature. The prepared coating not only shows superhydrophobicity but also durability in acidic/alkali solutions, as well as thermal and mechanical stability.

\section{Materials and Methods}

\subsection{Surface Preparation and Characterization}

The superhydrophobic surface was obtained from a dispersion of polytetrafluoroethylene (PTFE) powder (average diameter $\approx 1 \mu \mathrm{m}$ ) in a solution of polystyrene (PS) dissolved in ethyl acetate (EtOAc). The ethyl acetate was supplied by Sigma-Aldrich (St. Louis, MO, USA) with a purity grade $>99 \%$ and was used as received, PS was obtained through 
recycling commercial packaging waste. For the contact angle measurements high-purity grade water, produced by a MilliQ (Milli-Pore, Elix plus Milli-Q, Burlington, VT, USA) ion-exchange purifier with microfiltration stage $(18 \mathrm{M} \Omega \mathrm{cm})$ was utilized. Pure water surface tension was measured by a PAT- 1 tensiometer (Sinterface, Berlin, Germany) at $20{ }^{\circ} \mathrm{C}$ stable for several hours at $72.5 \pm 0.2 \mathrm{mN} / \mathrm{m}$.

The superhydrophobic surface was produced by spray-coating the PS/PTFE dispersion in EtOAc at room temperature and atmospheric conditions on a glass substrate. The coating was prepared using a constant distance of $10 \mathrm{~cm}$ between surface and airbrush, a pressure of 3 bar, and with different layer cycles (1-4) performed. The effect of the concentration of PS dispersed in EtOAc (0-10 g/L), keeping the concentration of PTFE constant, was studied.

For the evaluation of the wetting properties of the samples, static contact angle (CA) measurements were carried out by the ASTRA view tensiometer (developed at CNRICMATE, Genoa, Italy [58]) at room temperature. In order to assess the homogeneous character of the coating deposition, the data were collected in at least 3 different points of the surface. For measurement of the static contact angle, the droplet size should be smaller than the capillary length, but larger than the dimension of the structures on the surfaces. Droplets of about $5 \mathrm{~mm}^{3}$ in volume were gently deposited on the substrate using a microsyringe (Hamilton) with a stainless-steel capillary of $0.21 \mathrm{~mm}$ in diameter.

Morphological and microstructural aspects of the coatings were characterized by two complementary techniques: scanning electron microscopy (SEM) and 3D confocal and interferometric profilometry. SEM (LEO 1450VP, LEO Electron Microscopy Ltd., Cambridge, UK) was used for the characterization of the samples immediately after coating, as well as for the tested coatings. For better observation, all polymeric coatings were pre-treated with a gold conductive layer.

In order to evaluate the roughness and other important surface parameters of $\mathrm{SH}$ coating, 3D confocal and interferometric profilometry (Sensofar S-NEOX, Barcelona, Spain) was used according to the standard ISO 25178 and EUR 15178N. At least 3 measurements in different points were taken for each sample. The 3D profilometry was chosen to allow larger surface scans, such as the samples used in this work, and for its ease of use and the many parameters that it is capable to provide.

In particular, an experimentally obtained parameter was surface roughness (Sa), a dispersion parameter defined as the arithmetic mean of the absolute values of the surface deviations above and below the mean plane within the sampling area. The influence of a single movement on the measurement value therefore becomes extremely small, so that stable results can be obtained; Sa is a very general and commonly used parameter in practical applications and it is given in $\mathrm{nm}$ or $\mu \mathrm{m}$.

\subsection{Thermal Treatment}

Thermal tests were carried out to study the stability of prepared SHS at high temperature. The tests were performed in air atmosphere in a conventional furnace MF200X (F.lli Galli, Milan, Italy) with a chamber $(19 \times 26 \times 13 \mathrm{~cm})$ connected to an internal heating system: the tests consisted of a single cycle carried out for different times at different temperatures, as shown in Table 1 , with a rate of $3^{\circ} \mathrm{C} / \mathrm{min}$ during the heating and the cooling. The temperatures were chosen in consideration of the polystyrene melting point $\left(210-240^{\circ} \mathrm{C}\right.$ ) and its thermal decomposition (starting from $300^{\circ} \mathrm{C}$, with half decomposition at $363^{\circ} \mathrm{C}$ ) [59] and the duration was progressively increased after evidencing the absence of effect in the previous thermal treatment. 
Table 1. Preparation conditions, concentration of PS (g/L), and number of layers, for hydropho$\mathrm{bic/superhydrophobic} \mathrm{samples.}$

\begin{tabular}{cc}
\hline Time (h) & T $\left({ }^{\circ} \mathbf{C}\right)$ \\
\hline 3 & 200 \\
10 & 200 \\
30 & 200 \\
1 & 250 \\
30 & 280 \\
60 & 280 \\
1 & 280 \\
\hline
\end{tabular}

The upper temperatures, $280^{\circ} \mathrm{C}$ and $300^{\circ} \mathrm{C}$, were used to test the product in highly severe conditions. Successively, the sample was extracted from the furnace and cooled down at room temperature. The wettability of PS/PTFE coating was measured by an ASTRAview tensiometer and the surface sample was observed by a 3D profilometer in order to verify possible alterations to the topography induced by the thermal treatment.

\subsection{Wearing Test and Durability}

Since superhydrophobic materials can lose their properties as a result of impacts with external objects damaging their hierarchical structure, the coating resistance to the impact of suspended solids was set up to simulate the abrasion that occurs in a real aquatic environment. It may be considered as an alternative, and less invasive, solution with respect to classical tribological methods, by using a water dispersion of micrometric diatomaceous earth (DE, Sigma Aldrich) with or without $3.5 \mathrm{wt} \% \mathrm{NaCl}$. The DE was chosen for two primary reasons: first, the order of magnitude $(10-200 \mu \mathrm{m})$ of the particles potentially damaging the micro-nano roughness of SHS, resulting in a Cassie-Wenzel transition or even a partial removal of the coating; and, secondly, the wide presence of diatoms as unicellular algae in seawater, so simulating a potential environmental degradation. In order to simulate a more similar environment to real seawater, $\mathrm{NaCl}$ (3.5 wt \% in water) in $\mathrm{DE}$ dispersion was used to enhance aggressive conditions. Considering the range of suspended solid concentration, defined as transparent with $20 \mathrm{mg} / \mathrm{L}$ and turbid over $40 \mathrm{mg} / \mathrm{L}$ [60], the water/DE dispersion was prepared to be more concentrated $(0.5 \mathrm{~g} / \mathrm{L})$ with respect to actual sea water. The abrasion test was carried out for 7 days in conditions simulating a constantly moving fluid, specifically a constant speed of 3.8 knots corresponding to "light breeze" conditions [61]. The SH samples were constantly immersed, half of the time in the water/DE dispersion and then under the effect of the suspended solids. The volume of liquid was kept constant throughout the experiment. Such dispersion could be regarded as an accelerated and non-destructive ageing method.

\subsection{Resistance to Acid and Base}

The chemical durability of the SH PS/PTFE coating under acidic or basic conditions was evaluated by $\mathrm{pH}$ tests and static contact angle measurements. This aspect is considered important for those applications where $\mathrm{pH}$ conditions could not be stable or intentionally kept far from neutrality.

SHS resistance in harsh conditions such as aqueous $\mathrm{HNO}_{3}$, a strong oxidizing agent, and $\mathrm{NaOH}$, one of the strongest bases, was investigated in $\mathrm{pH}$ range from 1 to 14 . It was evaluated by both measuring the static contact angle of a drop of the acidic or basic solutions [62] and by evaluating the water CA after the immersion of the SHS in solutions at different $\mathrm{pH}$ for different times [63]. The $\mathrm{pH}$ of the solution was measured with a $\mathrm{pH}$ meter sensION+ PH31 (HACH, Loveland, CO, USA). 


\subsection{Raining Test}

With the aim of simulating conditions occurring during rain and navigation, raining tests were performed on SH PS/PTFE coatings to investigate the resistance under continuous water drop impact. This type of testing is already reported in the literature $[54,64-66]$, often with various and not unambiguous timing and methodologies. The resistance test consisted of dripping water from a height of $10 \mathrm{~cm}$ down to the sample tilted by $5^{\circ}$ to allow the water to roll off. The droplet volume was about $60 \mu \mathrm{L}$ and the dripping rate was kept at 1 droplet per second [67] so that each drop had an impact velocity of $1.4 \mathrm{~ms}^{-1}$. A test lasting 14 consecutive hours, corresponding to about $3 \mathrm{~L}$ of water and 50,400 drops, was performed.

\section{Results}

\subsection{Surface Characterization and Wettability}

To obtain an SHS surface, different conditions, such as PS concentration and number of layers, were considered. Roughness alone cannot describe the wettability behavior of the coating, because superhydrophobicity is found over a large range of roughness, Sa from 0.66 to $3.64 \mu \mathrm{m}$, and samples with the same Sa can show different surface behavior, probably related to the ratio and concentration of starting polymers (Figure 1).

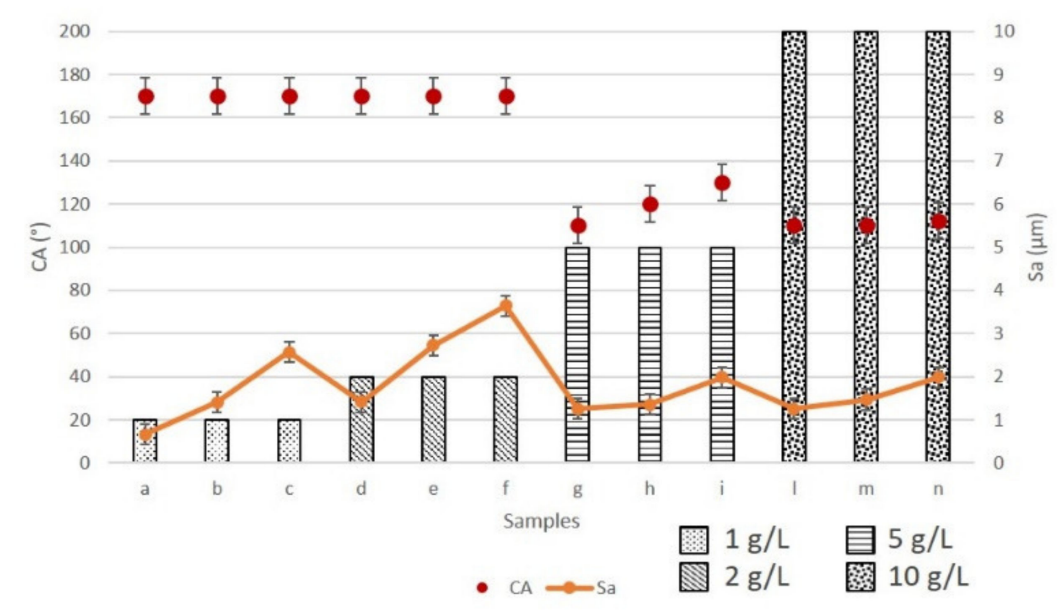

Figure 1. Relationship between CA, roughness (Sa) and PS concentration in preparation conditions. At lower PS concentrations (1-2 g/L), the coating is $\mathrm{SH}\left(\mathrm{CA}>160^{\circ}\right)$.

In particular, and in addition to roughness, the ratio between the two polymers can also significantly affect the hydrophobic behavior. An important effect on wettability is the amount of PS in the starting dispersion as reported in Figure 1 and observable in Figure 2 from contact angle images; by increasing its concentration, the CA decreases, allowing a kind of a fine tuning of the wettability properties.
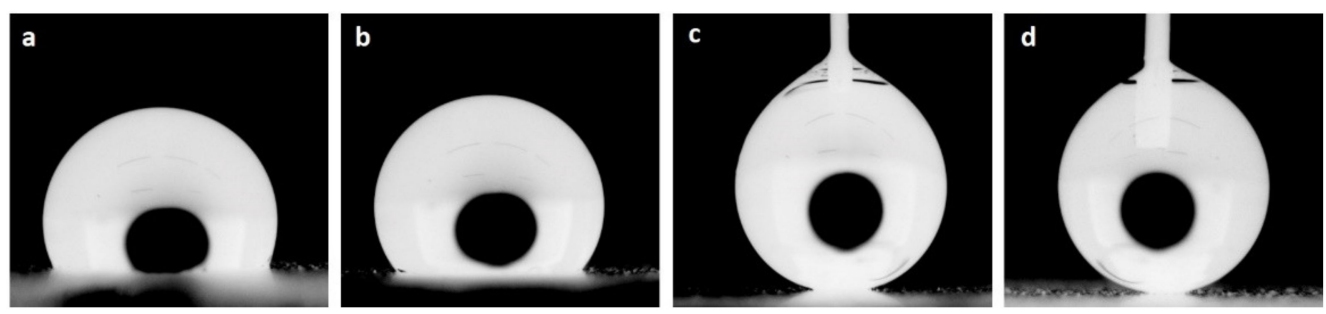

Figure 2. Contact angle images acquired on different PS/PTFE samples. (a) Sample " $n$ " $C A=112^{\circ}$, (b) sample " $i$ " $C A=130^{\circ}$, (c) sample "f" $\mathrm{CA}>170^{\circ}$, (d) sample "c" CA > 170. Droplet radius $1.2 \mathrm{~mm}$. 
This behavior was induced because PS embedded the PTFE particles, decreasing their effect on the surface energy component. This aspect was experimentally observed by SEM analysis. In Figure 3, two pictures and their sketches as lateral view are presented to demonstrate the influence of the PS concentration on surface morphology. In Figure 3a, the sample prepared with $10 \mathrm{~g} / \mathrm{L}$ of PS, and in Figure $3 \mathrm{~b}$, the sample prepared with $1 \mathrm{~g} / \mathrm{L}$ of PS are reported. The two samples show different morphologies, in particular, the sample with higher PS concentration appears homogeneous but with a typical structure of dry PS only (Figure 3c). In samples at lower PS concentrations, this effect is absent, the surface appears homogeneous and rough due to the presence of PTFE particles surfacing from the PS matrix.
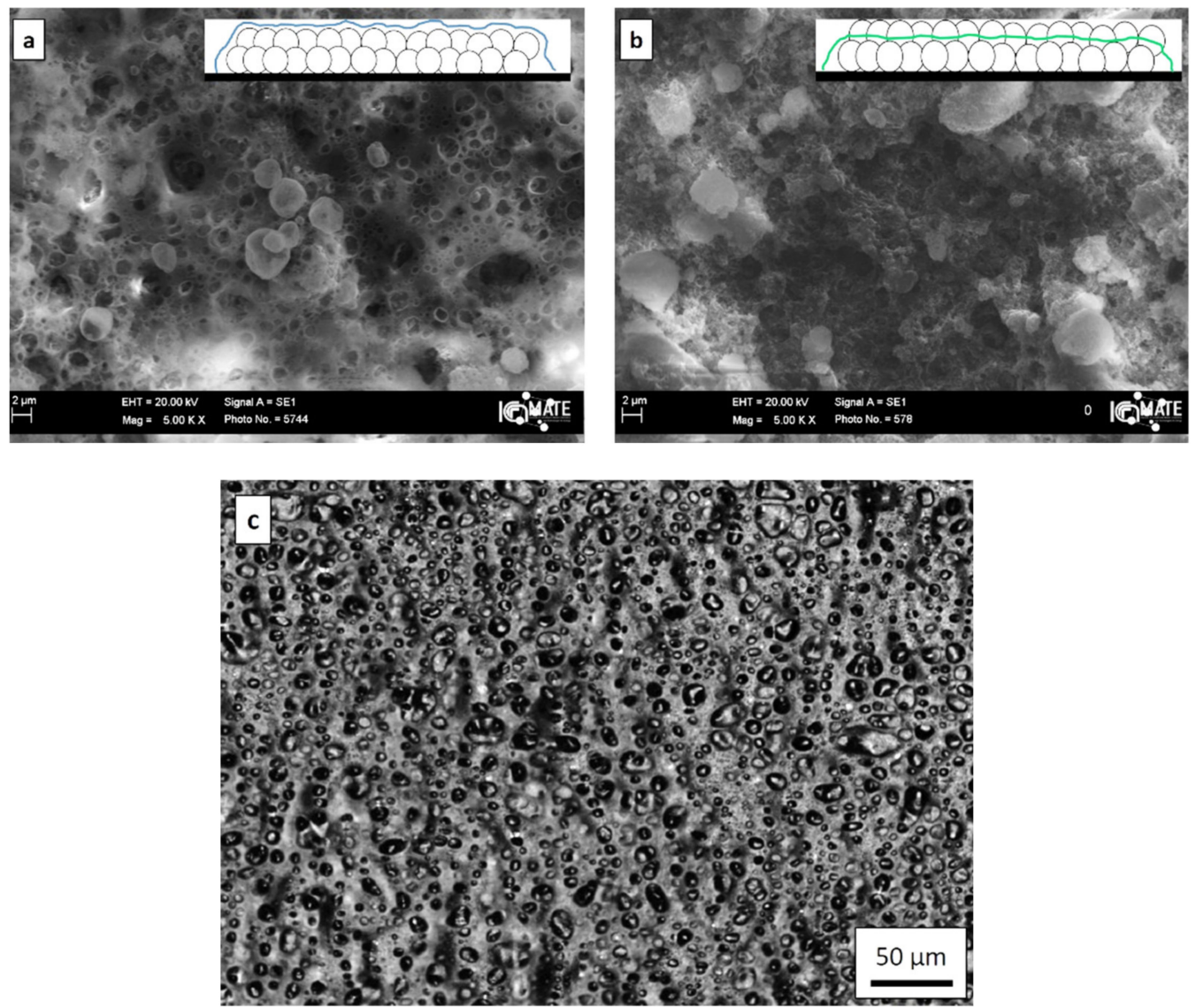

Figure 3. (a) A $2500 \times$ SEM image of $10 \mathrm{~g} / \mathrm{L}$ PS and its schematic lateral view, (b) $2500 \times$ SEM images of $1 \mathrm{~g} / \mathrm{L}$ PS and its schematic lateral view, (c) dry sprayed coating of PS only.

Another important observation regards the influence of the presence of PS in the starting dispersion. In Figure 4, two images of coatings produced by a solution of PTFE dispersed in only EtOAc are presented. In Figure 4a, the sample without PS appears less homogeneous and with holes as detailed in Figure $4 \mathrm{~b}$ at higher magnification $(10,000 \times)$.

In Figure 5, the effect of the PS on the PTFE powder particles aggregation can be observed at high magnification. In particular, in Figure $5 a, b$, samples without PS matrix, and coating produced with the dispersion prepared with $1 \mathrm{~g} / \mathrm{L}$ of PS/PTFE in EtOAc are reported, respectively. The presence of PS enabled the particles to bind making their dispersal more homogeneous in the ethyl acetate during the spray coating. 

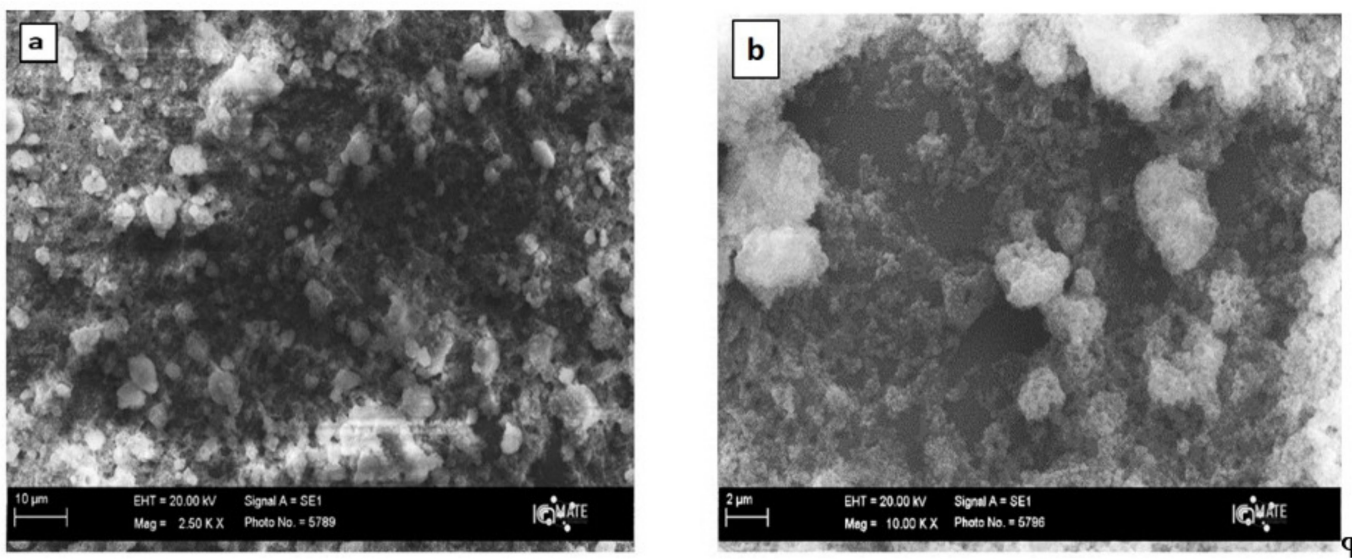

Figure 4. (a) A $2500 \times$ sample without PS; (b) 10,000 $\times$ holes on samples without PS and only PTFE particles.
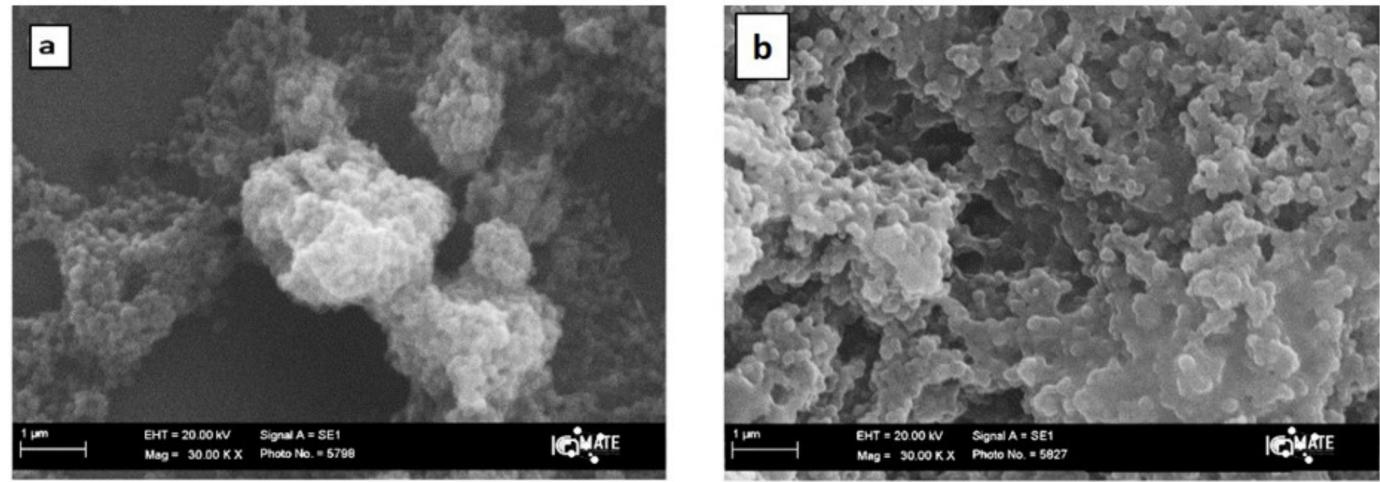

Figure 5. SEM images at 30,000×: (a) coating without PS and (b) coating with $1 \mathrm{~g} / \mathrm{L}$ of PS.

\subsection{Resistance to Acid and Base}

As previously described, we studied the behavior under aggressive conditions in order to imagine a possible application in a real environment. In the present case, the tests were performed with sodium hydroxide $(\mathrm{NaOH})$ and nitric acid $\left(\mathrm{HNO}_{3}\right)$ at different concentrations to test different $\mathrm{pH}$ conditions. In the first experiment, the coating maintained its superhydrophobicity for each tested $\mathrm{pH}$ during the contact of the drop and after its removal. In particular, the measured CA was the same as before the measurements $\left(\mathrm{CA}>170^{\circ}\right)$ and was constant in the whole studied $\mathrm{pH}$ range. In a more dynamic test, acid and basic solution drops bounced without friction and rolled off the surface (see Supplementary Materials). The surface analysis, performed with 3D profilometer, has confirmed that no change in roughness occurred.

The second $\mathrm{pH}$ test consisted of an immersion, for at least $24 \mathrm{~h}$, in a solution at different $\mathrm{pH}$ levels in the range of 1-14; the coating was always stable, maintaining its superhydrophobicity. In particular, the surface did not require washing after immersion in aggressive solutions to recover its special wettability. After each immersion, the samples were observed with a 3D profilometer to see if their roughness was altered by the aggressive solutions. For each test superhydrophobicity was kept and, also, the roughness of the immersed sample had the same value as the un-immersed sample used as a reference. The PS/PTFE coating was shown to be completely inert in the full $\mathrm{pH}$ range (0-14). This feature was probably due to the chemical inertness of the starting materials; in the literature [68], it was found that both PS and PTFE were not damaged by inorganic acid or base at room temperature. 


\subsection{Wearing Test}

Abrasion tests with diatomaceous earth (DE) dispersion $(0.5 \mathrm{~g} / \mathrm{L})$ at 3.8 knots on PS/PTFE coatings were carried out and, after 7 days of immersion, the coating started to lose its superhydrophobic behavior; in fact, water drops remained attached on some parts of the surface. To understand the causes, coating with approximately $2 \mu \mathrm{m}$ Sa was investigated with the 3D profilometer. In Figure 6 a 2D profilometer image of the coating is reported.

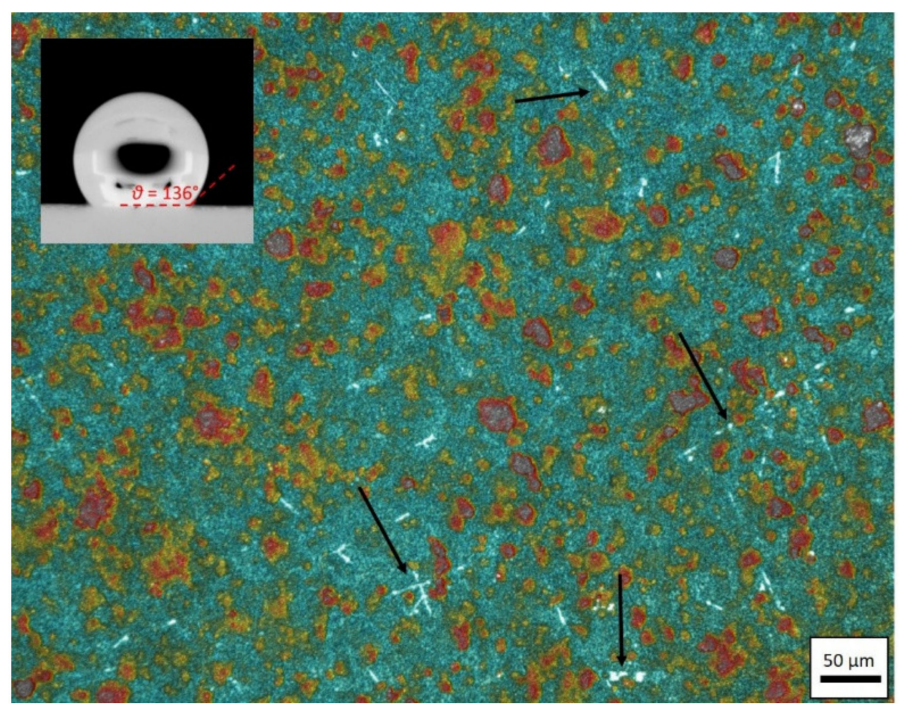

Figure 6. Two-dimensional image from the profilometer of PS/PTFE coating immersed in DE dispersion after 6 days. On the right side of the picture are many micrometric, large scratches due to the circulation of the DE particles. The drop picture shows the partial loss of SH properties.

The image shows the presence of some small scratches, indicated by arrows, about $10 \mu \mathrm{m}$ wide, at different points of the surface. The presence of these micrometric defects explains the partial loss of superhydrophobicity. DE particles may have damaged the coating because the surface presents a micrometric primary structure and because it was softer with respect to the DE particles.

\subsection{Thermal Treatment}

A thermal resistance experiment on spray-coated superhydrophobic surfaces was performed. The test consisted of multiple single-cycle thermal treatments carried out at different temperatures for different times (Table 1). After cooling, the wettability of the PS/PTFE coating was measured considering the CA, the SH behavior was maintained at the end of each heating cycle, including that of $300^{\circ} \mathrm{C}$ for $1 \mathrm{~h}$, evidencing the absence of morphological modifications even well beyond the melting point $\left(210-240^{\circ} \mathrm{C}\right)$. Water drops bounced without friction and rolled off the surface (see Supplementary Materials).

\subsection{Raining Test}

In order to evaluate the robustness of our superhydrophobic films, experiments of drops impacting on these surfaces were carried out. The experimental conditions are described in Section 2.5. The test was performed in one long cycle of $14 \mathrm{~h}$ corresponding to about 50,400 drops. The special wettability was maintained during the test and after $14 \mathrm{~h}$ with the surface roughness resulting unaltered in the drop impact area (Figure 7). Moreover, the coating resistance allowed the mechanical stress produced by the drop impact to be borne in the tested condition and avoid material loss. 


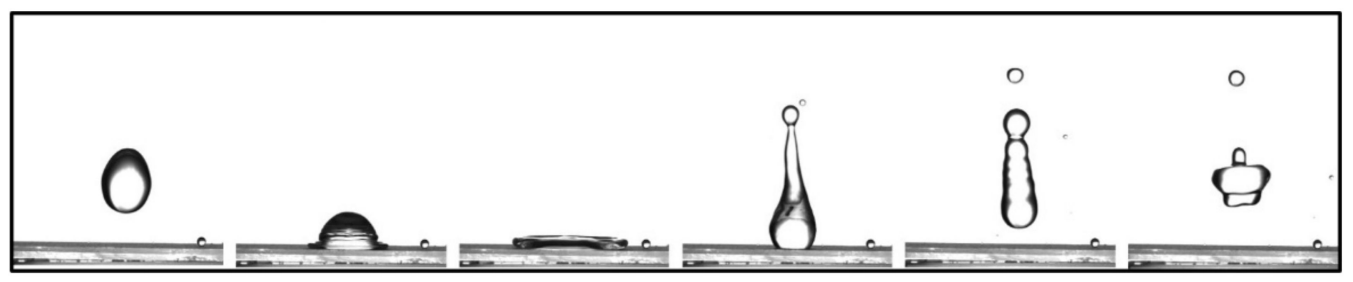

Figure 7. Slow motion sequence acquired by high-speed camera at $3500 \mathrm{fps}$ (Sprinter HD, Optronis) on superhydrophobic surface after $14 \mathrm{~h}$ of raining test.

\section{Conclusions}

In summary, a superhydrophobic (SH) coating made by recyclable polymers, polystyrene from packaging, and PTFE powder was successfully prepared on glass substrate using a spraycoating technique. The use of spray allows large, homogeneous flawless superhydrophobic surfaces to be obtained at room temperature without preliminary substrate preparation showing a water $\mathrm{CA}$ up to $170^{\circ}$ and sliding angle less than $5^{\circ}$ in agreement with the literature data $[43,48,53,55,69-71]$. It can be regarded as an alternative technique with respect to spin coating [72]. From this study, it was observed that, to obtain an SHS, the presence of nanoscale roughness is not strictly necessary, as it was observed for PS/PTFE surface of micrometric scale roughness.

The superhydrophobic PS/PTFE surface is not only highly water repellent but also stable in aggressive conditions. This feature was investigated by laboratory tests that included wearing, thermal treatment, $\mathrm{pH}$ test, and continuous drop impact (raining test). The produced SHS can resist a longer cycle of water drop impact $(14 \mathrm{~h})$ with respect to literature data [67], an immersion in aggressive solution with $\mathrm{pH}$ ranging from 1 to 14 , and severe thermal treatment (up to $300^{\circ} \mathrm{C}$ ).

Supplementary Materials: The following are available online at https:/ /www.mdpi.com/article/10

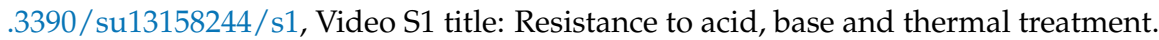

Author Contributions: Conceptualization, methodology, funding acquisition, M.F.; data analysis, M.F. and F.C.; investigation, F.C.; writing original draft, M.F. and F.C.; writing-review and editing, M.F. and F.C. All authors have read and agreed to the published version of the manuscript.

Funding: This research was funded by the Fondazione Bancaria Compagnia di San Paolo, Turin, ID ROL 20718, the Project ANFISOL-Design and the development of superamphiphobic coatings with self-cleaning properties for photovoltaic panels.

Data Availability Statement: Not available.

Acknowledgments: The authors acknowledge the support of Fondazione Bancaria Compagnia di San Paolo, Turin. This work was performed within the framework of the Project ANFISOL Design and development of superamphiphobic coatings with self-cleaning properties for photovoltaic panels (ID ROL 20718) funded by the Fondazione Bancaria Compagnia di San Paolo, Turin.

Conflicts of Interest: The authors declare no conflict of interest.

\section{References}

1. Barthlott, W.; Ehler, N. Raster-Elektronenmikroskopie der Epidermis-Oberflächen von Spermatophyten. Akad. Wiss. Lit. 1977, 19, 367-465.

2. Barthlott, W.; Neinhuis, C. Purity of the sacred lotus, or escape from contamination in biological surfaces. Planta 1997, 202, 1-8. [CrossRef]

3. Wagner, T.; Neinhuis, C.; Barthlott, W. Wettability and Contaminability of Insect Wings as a Function of Their Surface Sculptures. Acta Zool. 1996, 77, 213-225. [CrossRef]

4. Zhai, L.; Berg, M.C.; Cebeci, F.Ç.; Kim, Y.; Milwid, J.M.; Rubner, M.F.; Cohen, R.E. Patterned superhydrophobic surfaces: Toward a synthetic mimic of the namib desert beetle. Nano Lett. 2006, 6, 1213-1217. [CrossRef]

5. Watson, G.S.; Gellender, M.; Watson, J.A. Self-propulsion of dew drops on lotus leaves: A potential mechanism for self-cleaning. Biofouling 2014, 30, 427-434. [CrossRef] [PubMed]

6. Parker, A.R.; Lawrence, C.R. Water capture by a desert beetle. Nature 2001, 414, 33-34. [CrossRef] [PubMed]

7. Bixler, G.D.; Bhushan, B. Fluid drag reduction and efficient self-cleaning with rice leaf and butterfly wing bioinspired surfaces. Nanoscale 2013, 5, 7685-7710. [CrossRef] [PubMed] 
8. Zhang, D.; Wang, L.; Qian, H.; Li, X. Superhydrophobic surfaces for corrosion protection: A review of recent progresses and future directions. J. Coat. Technol. Res. 2016, 13, 11-29. [CrossRef]

9. Feng, L.; Zhang, H.; Wang, Z.; Liu, Y. Superhydrophobic aluminum alloy surface: Fabrication, structure, and corrosion resistance. Colloids Surf. Physicochem. Eng. Asp. 2014, 441, 319-325. [CrossRef]

10. Jin, C.; Li, J.; Han, S.; Wang, J.; Sun, Q. A durable, superhydrophobic, superoleophobic and corrosion-resistant coating with rose-like ZnO nanoflowers on a bamboo surface. Appl. Surf. Sci. 2014, 320, 322-327. [CrossRef]

11. Arnott, J.; Wu, A.H.F.; Vucko, M.J.; Lamb, R.N. Marine antifouling from thin air. Biofouling 2014, 30, 1045-1054. [CrossRef]

12. Detty, M.R.; Drake, D.R.; Tang, Y.; Bright, F. Hybrid anti-fouling coating compositions and methods for preventing the fouling of surfaces subjected to a marine environment. U.S. Patent 7244295, 17 July 2007.

13. Dong, H.; Cheng, M.; Zhang, Y.; Wei, H.; Shi, F. Extraordinary drag-reducing effect of a superhydrophobic coating on a macroscopic model ship at high speed. J. Mater. Chem. 2013, 1, 5886-5891. [CrossRef]

14. Brassard, J.-D.; Sarkar, D.K.; Perron, J. Studies of drag on the nanocomposite superhydrophobic surfaces. Appl. Surf. Sci. 2015, 324, 525-531. [CrossRef]

15. Pu, X.; Li, G.; Huang, H. Preparation, anti-biofouling and drag-reduction properties of a biomimetic shark skin surface. Biol. Open 2016, 5, 389-396. [CrossRef]

16. Privett, B.J.; Youn, J.; Hong, S.a.; Lee, J.; Han, J.; Shin, J.H.; Schoenfisch, M.H. Antibacterial fluorinated silica colloid superhydrophobic surfaces. Langmuir 2011, 27, 9597-9601. [CrossRef] [PubMed]

17. Heinonen, S.; Huttunen-Saarivirta, E.; Nikkanen, J.-P.; Raulio, M.; Priha, O.; Laakso, J.; Storgårds, E.; Levänen, E. Antibacterial properties and chemical stability of superhydrophobic silver-containing surface produced by sol-gel route. Colloids Surf. Physicochem. Eng. Asp. 2014, 453, 149-161. [CrossRef]

18. Cao, L.; Jones, A.K.; Sikka, V.K.; Wu, J.; Gao, D. Anti-Icing superhydrophobic coatings. Langmuir 2009, 25, 12444-12448. [CrossRef] [PubMed]

19. Lv, J.; Song, Y.; Jiang, L.; Wang, J. Bio-inspired strategies for anti-icing. ACS Nano 2014, 8, 3152-3169. [CrossRef]

20. Ruan, M.; Zhan, Y.; Wu, Y.; Wang, X.; Li, W.; Chen, Y.; Wei, M.; Wang, X.; Deng, X. Preparation of PTFE/PDMS superhydrophobic coating and its anti-icing performance. RSC Adv. 2017, 7, 41339-41344. [CrossRef]

21. Ying, J.; Eid, K.F.; Sommers, A.D. Designing Energy-Efficient Heat Exchangers-Creating Micro-Channels On The Aluminum Fin Surface. Int. Refrig. Air Cond. Conf. 2010, 2836, 1-8.

22. Cassie, A.B.D.; Baxter, S. Wettability of porous surfaces. Trans. Faraday Soc. 1944, 40, 546-551. [CrossRef]

23. Ishizaki, T.; Hieda, J.; Saito, N.; Saito, N.; Takai, O. Corrosion resistance and chemical stability of super-hydrophobic film deposited on magnesium alloy AZ31 by microwave plasma-enhanced chemical vapor deposition. Electrochim. Acta 2010, 55, 7094-7101. [CrossRef]

24. Vilaró, I.; Yagüe, J.L.; Borros, S. Superhydrophobic copper surfaces with anti-corrosion properties fabricated by solventless CVD methods. ACS Appl. Mater. Interfaces 2016, 9, 1057-1065. [CrossRef]

25. Li, B.J.; Li, H.; Huang, L.J.; Ren, N.F.; Kong, X. Femtosecond pulsed laser textured titanium surfaces with stable superhydrophilicity and superhydrophobicity. Appl. Surf. Sci. 2016, 389, 585-593. [CrossRef]

26. Wu, L.K.; Hu, J.M.; Zhang, J.Q. One step sol-gel electrochemistry for the fabrication ofsuperhydrophobic surfaces. J. Mater. Chem. 2013, 1, 14471-14475. [CrossRef]

27. Zhang, X.; Zheng, F.; Ye, L.; Xiong, P.; Yan, L.; Yang, W.; Jiang, B. A one-pot sol-gel process to prepare a superhydrophobic and environment-resistant thin film from ORMOSIL nanoparticles. RSC Adv. 2014, 4, 9838. [CrossRef]

28. Wang, J.; Ren, K.; Chang, H.; Zhang, S.; Jin, L.; Ji, J. Facile fabrication of robust superhydrophobic multilayered film based on bioinspired poly(dopamine)-modified carbon nanotubes. Phys. Chem. Chem. Phys. 2014, 16, 2936-2943. [CrossRef] [PubMed]

29. Su, F.; Yao, K. Facile Fabrication of Superhydrophobic Surface with Excellent Mechanical Abrasion and Corrosion Resistance on Copper Substrate by a Novel Method. ACS Appl. Mater. Interfaces 2014, 6, 8762-8770. [CrossRef]

30. Wang, D.; Zhang, Z.; Li, Y.; Xu, C. Highly transparent and durable superhydrophobic hybrid nanoporous coatings fabricated from polysiloxane. ACS Appl. Mater. Interfaces 2014, 6, 10014-10021. [CrossRef] [PubMed]

31. Pi, P.; Mu, W.; Fei, G.; Deng, Y. Superhydrophobic film fabricated by controlled microphase separation of PEO-PLA mixture and its transparence property. Appl. Surf. Sci. 2013, 273, 184-191. [CrossRef]

32. Davaasuren, G.; Ngo, C.V.; Oh, H.S.; Chun, D.M. Geometric study of transparent superhydrophobic surfaces of molded and grid patterned polydimethylsiloxane. Appl. Surf. Sci. 2014, 314, 530-536. [CrossRef]

33. Wang, M.F.; Raghunathan, N.; Ziaie, B. A nonlithographic top-down electrochemical approach for creating hierarchical (micronano) superhydrophobic silicon surfaces. Langmuir 2007, 23, 2300-2303. [CrossRef] [PubMed]

34. Feng, J.; Tuominen, M.T.; Rothstein, J.P. Hierarchical superhydrophobic surfaces fabricated by dual-scale electron-beamlithography with well-ordered secondary nanostructures. Adv. Funct. Mater. 2011, 21, 3715-3722. [CrossRef]

35. Wong, H.S.; Barakat, R.; Alhilali, A.; Saleh, M.; Cheeseman, C.R. Hydrophobic concrete using waste paper sludge ash. Cem. Concr. Res. 2015, 70, 9-20. [CrossRef]

36. Shen, L.; Qiu, W.; Liu, B.; Guo, Q. Stable superhydrophobic surface based on silicone combustion product. RSC Adv. 2014, 4, 56259-56262. [CrossRef]

37. Guo, L.P.; Sun, W.; Yu, T.; Feng, M.Z. Preparation and characteristics of a recycled cement-based superhydrophobic coating with dirt pickup resistance. Sci. China Technol. Sci. 2015, 58, 1096-1104. [CrossRef] 
38. Wen, G.; Huang, J.X.; Guo, Z.G. Energy-effective superhydrophobic nanocoating based on recycled eggshell. Colloids Surf. Physicochem. Eng. Asp. 2019, 568, 20-28. [CrossRef]

39. Ray, S.S.; Gandhi, M.; Chen, S.S.; Chang, H.M.; Dan, C.T.N.; Le, H.Q. Anti-wetting behaviour of a superhydrophobic octadecyltrimethoxysilane blended PVDF/recycled carbon black composite membrane for enhanced desalination. Environ. Sci. Water Res. Technol. 2018, 4, 1612-1623. [CrossRef]

40. Lin, Y.T.; Chou, J.H. Fabricating curved super-hydrophobic surfaces greenly using recycled polypropylene. Int. J. Plast. Technol. 2016, 20, 1-10. [CrossRef]

41. Accudynetest. Critical Surface Tension and Contact Angle with Water for Various Polymers. 2009. Available online: https: //www.accudynetest.com/polytable_03.html?sortby=contact_angle (accessed on 13 September 2019).

42. Salapare, H.S.; Guittard, F.; Noblin, X.; de Givenchy, E.T.; Celestini, F.; Ramos, H.J. Stability of the hydrophilic and superhydrophobic properties of oxygen plasma-treated poly(tetrafluoroethylene) surfaces. J. Colloid Interface Sci. 2013, 396, 287-292. [CrossRef]

43. Zhu, Y.; He, Y.; Zhang, J.F.; Li, Z.H.; Zhou, W.; Yang, D.Q.; Sacher, E. Preparation of large-scale, durable, superhydrophobic PTFE films using rough glass templates. Surf. Interface Anal. 2017, 49, 1422-1430. [CrossRef]

44. Jiang, C.; Hou, W.; Wang, Q.; Wang, T. Facile fabrication of superhydrophobic polytetrafluoroethylene surface by cold pressing and sintering. Appl. Surf. Sci. 2011, 257, 4821-4825. [CrossRef]

45. Nilsson, M.A.; Daniello, R.J.; Rothstein, J.P. A novel and inexpensive technique for creating superhydrophobic surfaces using Teflon and sandpaper. J. Phys. Appl. Phys. 2010, 43, 045301. [CrossRef]

46. Zhan, Y.L.; Ruan, M.; Li, W.; Li, H.; Hu, L.Y.; Ma, F.M.; Yu, Z.L.; Feng, W. Fabrication of anisotropic PTFE superhydrophobic surfaces using laser microprocessing and their self-cleaning and anti-icing behavior. Colloids Surf. Physicochem. Eng. Asp. 2017, 535, 8-15. [CrossRef]

47. Xu, Z.; Wang, L.; Yu, C.; Li, K.; Tian, Y.; Jiang, L. In Situ Separation of Chemical Reaction Systems Based on a Special Wettable PTFE Membrane. Adv. Funct. Mater. 2018, 28, 1703970. [CrossRef]

48. Fang, Y.; Yong, J.; Chen, F.; Huo, J.; Yang, Q.; Bian, H.; Du, G.; Hou, X. Durability of the tunable adhesive superhydrophobic PTFE surfaces for harsh environment applications. Appl. Phys. 2016, 122, 827. [CrossRef]

49. Kecskeméti, G.; Hopp, B.; Smausz, T.; Tóth, Z.; Szabó, G. Production of porous PTFE-Ag composite thin films by pulsed laser deposition. Appl. Surf. Sci. 2012, 258, 7982-7988. [CrossRef]

50. Bodas, D.S.; Mandale, A.B.; Gangal, S.A. Deposition of PTFE thin films by RF plasma sputtering on $\langle 100\rangle$ silicon substrates. Appl. Surf. Sci. 2005, 245, 202-207. [CrossRef]

51. Tripathi, S.; De, R.; Haque, S.M.; Rao, K.D.; Misal, J.S.; Prathap, C.; Das, S.C.; Patidar, M.M.; Ganesan, V.; Sahoo, N.K. Annealing dependent evolution of columnar nanostructures in RF magnetron sputtered PTFE films for hydrophobic applications. Mater. Res. Express. 2018, 5, 015312. [CrossRef]

52. Zhang, Z.X.; Zhang, T.; Zhang, X.; Xin, Z.; Prakashan, K. Fabrication of a thin-layer PTFE coating exhibiting superhydrophobicity by supercritical $\mathrm{CO}_{2}$. Prog. Org. Coat. 2017, 111, 322-326. [CrossRef]

53. Qing, W.; Shi, X.; Deng, Y.; Zhang, W.; Wang, J.; Tang, C.Y. Robust superhydrophobic-superoleophilic polytetrafluoroethylene nanofibrous membrane for oil/water separation. J. Membr. Sci. 2017, 540, 354-361. [CrossRef]

54. Zhuang, A.; Liao, R.; Dixon, S.C.; Lu, Y.; Sathasivam, S.; Parkin, I.P.; Carmalt, C.J. Transparent superhydrophobic PTFE films via one-step aerosol assisted chemical vapor deposition. RSC Adv. 2017, 7, 29275-29283. [CrossRef]

55. Lei, S.; Shi, Z.; Ou, J.; Li, W.; Qiao, G.; Yu, X. A facile process for preparing superhydrophobic PBZ-PTFE coating with excellent stable properties. Appl. Phys. 2016, 122, 1011. [CrossRef]

56. Weng, R.; Zhang, H.; Liu, X. Spray-coating process in preparing PTFE-PPS composite super-hydrophobic coating. AIP Adv. 2014, 4, 031327. [CrossRef]

57. Pawar, P.G.; Xing, R.; Kambale, R.C.; Kumar, A.M.; Liu, S.; Latthe, S.S. Polystyrene assisted superhydrophobic silica coatings with surface protection and self-cleaning approach. Prog. Org. Coat. 2017, 105, 235-244. [CrossRef]

58. Liggieri, L.; Passerone, A. An automatic technique for measuring the surface tension of liquid metals. High Temp. Technol. 1989, 7 , 82-86. [CrossRef]

59. Kumudine, C.; Premachandra, J. Polymer Data Handbook; American Chemical Society: Washington, DC, USA, 1999.

60. Michigan Department of Environmental Quality. Michigan's Water Chemistry Monitoring Program; EGLE: Lansing, MI, USA, 2013.

61. Met Office. The Beaufort Scale; National Meteorological Library and Archive: London, UK, 2010; pp. 1-22.

62. Li, K.; Zeng, X.; Li, H.; Lai, X. Fabrication and characterization of stable superhydrophobic fluorinated-polyacrylate/silica hybrid coating. Appl. Surf. Sci. 2014, 298, 214-220. [CrossRef]

63. Wang, L.; Yang, J.; Zhu, Y.; Li, Z.; Sheng, T.; Hu, Y.M.; Yang, D.Q. A study of the mechanical and chemical durability of Ultra-Ever Dry Superhydrophobic coating on low carbon steel surface. Colloids Surf. Physicochem. Eng. Asp. 2016, 497, 16-27. [CrossRef]

64. Liang, Z.; Zhou, Z.; Zhao, L.; Dong, B.; Wang, S. Fabrication of transparent, durable and self-cleaning superhydrophobic coatings for solar cells. New J. Chem. 2020, 44, 14481-14489. [CrossRef]

65. Huang, W.-H.; Lin, C.-S. Robust superhydrophobic transparent coatings fabricated by a low-temperature sol-gel process. Appl. Surf. Sci. 2014, 305, 702-709. [CrossRef]

66. Liu, X.; Wang, Y.; Chen, Z.; Ben, K.; Guan, Z. A self-modification approach toward transparent superhydrophobic glass for rainproofing and superhydrophobic fiberglass mesh for oil-water separation. Appl. Surf. Sci. 2016, 360, 789-797. [CrossRef] 
67. Xu, Q.F.; Wang, J.N.; Smith, I.H.; Sanderson, K.D. Superhydrophobic and transparent coatings based on removable polymeric spheres. J. Mater. Chem. 2009, 19, 655-660. [CrossRef]

68. Labware Chemical Resistance Table; Thermo Fisher Scientific Inc: Waltham, MA, USA, 2015; pp. 1-15.

69. Zhu, W.; Liu, H.; Yan, W.; Chen, T. The fabrication of superhydrophobic PTFE/UHMWPE composite surface by hot-pressing and texturing process. Colloid Polym. Sci. 2017, 295, 759-766. [CrossRef]

70. Burkarter, E.; Saul, C.K.; Thomazi, F.; Cruz, N.C.; Roman, L.S.; Schreiner, W.H. Superhydrophobic electrosprayed PTFE. Surf. Coat. Technol. 2007, 202, 194-198. [CrossRef]

71. Young, T.J.; Jackson, J.; Roy, S.; Ceylan, H.; Sundararajan, S. Tribological behavior and wettability of spray-coated superhydrophobic coatings on aluminum. Wear 2017, 376, 1713-1719. [CrossRef]

72. Baba, E.M.; Cansoy, C.E.; Zayim, E.O. Investigation of wettability and optical properties of superhydrophobic polystyrene-SiO ${ }_{2}$ composite surfaces. Prog. Org. Coat. 2016, 99, 378-385. [CrossRef] 